\title{
Pengaruh Motivasi Instrinsik, Kompetensi dan Pengawasan Pimpinan Terhadap Kinerja Pegawai Dinas Perhubungan Kota Gunungsitoli
}

\section{Impact Of Intrinsic Motivation, Compensation and Supervision of Leaders On Employee Performance Of Departement Of Transportation of Gunungsitoli}

\author{
Erwin Meiman Larosa ${ }^{\left(1^{*}\right)} \&$ Sri Gustina Pane ${ }^{(2)}$

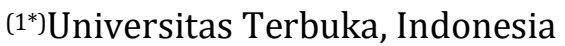 \\ (2)Universitas Islam Sumatera Utara,Indonesia
}

Disubmit: 22 Oktober 2021; Diproses: 02November 2021; Diaccept: 12 November 2021; Dipublish: 02 Desember 2021

*Corresponding author: E-mail: bp748181@gmail.com

\begin{abstract}
Abstrak
Penelitian ini bertujuan untuk mengetahui dan menganalisis seberapa besar Pengaruh Motivasi Instrinsik, Kompensasi dan Pengawasan Pimpinan terhadap Kinerja Pegawai Dinas Perhubungan Kota Gunungsitoli. Populasi dalam penelitian ini adalah seluruh pegawai di lingkungan Dinas Perhubungan Kota Gunungsitoli yang berjumlah 40 orang. Teknik pengambilan sampel yang digunakan dalam penelitian ini dengan menggunakan metode sensus dimana seluruh populasi menjadi sampel penelitian. Penelitian ini menggunakan metode penelitian korelasional. Data dianalisis dengan analisis statistik deskriptif dan regresi linear berganda. Pengumpulan data dalam penelitian ini menggunakan kuesioner yang diwujudkan dalam bentuk pernyataan. Hasil penelitian menunjukkan motivasi intrinsik berpengaruh positif dan signifikan terhadap kinerja pegawai di lingkungan Dinas Perhubungan Kota Gunungsitoli, kompensasi berpengaruh positif dan signifikan terhadap kinerja pegawai di lingkungan Dinas Perhubungan Kota Gunungsitoli, pengawasan pimpinan berpengaruh positif dan signifikan terhadap kinerja pegawai di lingkungan Dinas Perhubungan Kota Gunungsitoli dan secara simultan motivasi intrinsik, kompensasi dan pengawasan pimpinan berpengaruh positif dan signifikan terhadap kinerja pegawai di lingkungan Dinas Perhubungan Kota Gunungsitoli.
\end{abstract}

Kata Kunci: Motivasi; Kompetensi; Pengawasan

\begin{abstract}
The purpose of this study is to determine and analyze the impact of intrinsic motivation, compensation and supervision of leaders on employee performance of Department of Transportation of Gunungsitoli. The census method was used in this study, with a total of 40 samples drawn from the entire population. This study uses correlational research methods. Data were collected by questionnaires. Research data collected by using questionnaire method and data analysis used are descriptive statistical analysis and Multiple linear regressions. The findings revealed that the intrinsic motivation has a positive and significant impact on employee performance of Department of Transportation of Gunungsitoli, the compensation has a positive and significant impact on employee performance of Department of Transportation of Gunungsitoli, supervision of leaders has a positive and significant impact on employee performance of Department of Transportation of Gunungsitoli, intrinsic motivation, compensation and supervision of leaders all have a positive and significant impact on employee performance of Department of Transportation of Gunungsitoli
\end{abstract}

Keywords: Motivation; Competension; Supervisore

Rekomendasi mensitasi :

Larosa, E.M. \& Pane, S.G. (2021), Pengaruh Motivasi Instrinsik, Kompetensi dan Pengawasan Pimpinan Terhadap Kinerja Pegawai Dinas Perhubungan Kota Gunungsitoli. Jurnal Penelitian Pendidikan, Psikologi dan Kesehatan (J-P3K), 2 (3): 268-274. 


\section{PENDAHULUAN}

Instansi Pemerintah yang sifatnya memberikan pelayanan kepada masyarakat salah satunya kantor Dinas Perhubungan Kota Gunungsitoli dan beberapa kantor pemerintah lainnya, peranan pegawai dalam hal ini sangat penting. Sebagaimana yang berkembang di Dinas Perhubungan Kota Gunungsitoli merupakan dinas yang memberikan pelayanan bagi masyarakat. Adanya selisih yang terjadi pada target serta realisasi yang di alami oleh pemerintah dapat terlihat bahwa terdapat GAP pada usaha capaian target dengan realisasi yang terdapat pada Laporan Kinerja Perangkat Daerah Dinas Perhubungan Kota Gunungsitoli.

Capaian kinerja Dinas Perhubungan Kota Gunungsitoli dalam capaian Pendapatan Asli Daerah di bidang perhubungan sebesar 57, 48\%. Hal ini menggambarkan tingkat pencapaian kinerja tahun 2019 Dinas Perhubungan Kota Gunungsitoli yang masih belum mencapai target kegiatan yang sudah direncanakan dalam menunjang visi dan misi Pemerintah Kota Gunungsitoli yang "Nyaman, Aman dan Berdaya Saing".

Faktor ketidaktercapaian kinerja tersebut dipengaruhi oleh Faktor Motivasi secara instriksik, kompetensi, serta pengawasan pimpinan dengan melihat dampak dari kinerja pegawai(Satria \& Kuswara, 2013). Faktor tersebut menjadi masalah yang cukup penting untuk diperoleh solusi sehingga kinerja terus meningkat dan berkelanjutan. Berdasarkan pengamatan yang dilakukan motivasi instrinsik menuru sebagaimana mereka menyelesaikan pekerjaan, motivasi instrinsik yang kurang sehingga pegawai terlambat dalam melaksanakan pekerjaan dan tidak begitu tanggap saat terdapat pekerjaan yang harus segera terselesaikan(Salawangi, 2019).

Dalam peningkatan kinerja, pegawai Dinas Perhubungan Kota Gunungsitoli diharapkan mampu memiliki motivasi instrinsik yang mendorong setiap pegawai untuk bekerja secara maksimal dalam mencapai sasaran kerja sesuai visi misi lembaga. Hal ini seiring dengan pendapat (Syamsurizal, 2021)menyatakan pendapat tersebut tergambar dengan jelas pentingnya instrinsik dimiliki oleh setiap pegawai Dinas Perhubungan Kota Gunungsitoli dalam menjali kegiatan dan aktivitas sehari hari di lembaga tersebut.

Dari hasil prasurvey yang dilaksanakan di lingkungan Dinas Perhubungan Kota Gunungsitoli dihubungan dengan Research Gap pada penelitian yang dilakukan sebelumnya dimana ada penelitian yang memperoleh hasil bahwa motivasi memiliki dampak positif serta signifikan pada kinerja karyawan. Sebagaimana penelitian(Saputra \& Anindita, 2021). Akan tetapi terdapat perbedaan hasil dari penelitian yang dilakukan(Kusuma \& Hidayat, 2021) yang memperoleh hasul bahwa motivasi tidak berpengaruh pada kinerja. Kinerja dipengaruhi faktor lain yakni kompensasi yang mana suatu tindakan untuk memfasilitasi pegawai seperti gaji, bonus, dan juga hadiah dengan tujuan agar pegawai termotivasi untuk berkinerja baik.

(Qustolani, 2018)Kompensasi dapat dimaknai dengan keseluruhan imbal jasa dari perusahaan yang mana mencerminkan sejauh mana upaya yang dilakukann organisasi untuk dapat 
mempertahankan serta meningkatkan kesejahteraan. Pemerintah Kota Gunungsitoli juga memberikan penghargaan kepada Aparatur Sipil Negara di lingkup Pemerintahanya berupa Pemberian Tambahan Penghasilan (TTP), dengan dasar hukum, pedoman, kriteria, serta ukuran indikator yang berlaku bagi seluruh sesuai dengan jenis dan kelas jabatan yang diampu. Tunjangan tersebut diharapkan mampu memberikan rangsangan terhadap semangat kerja pegawai yang akan berdampak kepada motivasi intrinsik dan kinerja pegawai. Kompensasi merupakan hal mendasar dalam manajemen sumber daya yang diharapkan mampu meningkatkan kinerja pegawai di lingkungan Dinas Perhubungan Kota Gunungsitoli.(Simarmata, 2021) menyatakan bahwa pemberian kompensasi diharapkan mampu meningkatkan kinerja pegawai dalam mencapai sasaran kinerja lembaga. Namun dari hasil capaian kinerja Dinas Perhubungan Kota Gunungsitoli tahun 2019 masih 79,83\% dan pencapaian target Pendapatan Asli Daerah di bidang perhubungan masih $57,48 \%$. Persentase pencapaian kinerja Dinas Perhubungan Kota Gunungsitoli tidak sejalan dengan semangat pemerintah daerah dalam pemberian TPP sebagai bagian kompensasi dalam peningkatan kinerja pegawai. Dari hasil prasurvey yang dilaksanakan di lingkungan Dinas Perhubungan Kota Gunungsitoli dihubungan dengan penelitian sebelumnya. Hal ini sejalan dengan penelitian dari (Budiman \& Steven, 2021) dan bertolak belakang dengan penelitian dari (Levina \& Haan, 2019) dan (Karundeng, 2013)

Dalam mengawasi pimpinan terdapat faktor yang mendukung agar kinerja tercapai. Perkembangan pengawasan menjadi sebuah sistem terkendali yang meletakkan pimpinan organisasi pada pihak yang menentukan serta menggerakan sehingga tujuan perusahaan tercapai. Terdapat banyak unsur dalam SPIP diantaranya ialah lingkungan pengendalian risiko, pengendalian, informasi dan komunikasi serta pemantauan yang menjadi pimpinan terdorong untuk menggeser pengawasan.

Peningkatan kinerja pegawai dapat tercapai jika pimpinan lembaga menerapkan standar operasi prosedur yang memadai bagi pegawai yang dapat memotivasi karyawan untuk bertindak optimal dalam kegiataan kerja sehari hari. Proses ini akan berjalan dengan baik jika perusahaan lembaga menerapkan konsep planning, directing, actuating dan controlling yang terjadwal dan tersistem dengan baik yang dikerjakan secara bersama sama oleh seluruh pemangku kepentingan dilembaga tersebut (Stephen et al., 2015). Keempat kegiatan tersebut dapat berjalan sesuai ketentuan dengan syarat lembaga menerapkan pengawasan oleh pimpinan lembaga tersebut. Pengawasan yang dilakukan pimpinan bertujuan memperbaiki dan dan memastikan tlembaga dapat tercapai sesuai target kerja yang telah ditentukan. Pengawasan merupakan fungsi manajerial yang keempat setelah bidang perencanaan maka kegiatan berikutnya adalah pengorganisasian, dan pengarahan (Tukiman et al., 2021). Dari hasil prasurvey tentang pengawasan yang 
dilaksanakan di lingkungan Dinas Perhubungan Kota Gunungsitoli dihubungkan penelitian terdahulu. Penelitian ini sejalan dengan (Putra et al., 2014) dan bertentangan dengan penelitian dari (Yaqin \& Kristanto, 2012)

Dari paparan tersebut penelitian melakukan penelitian dengan judul "Pengaruh Motivasi Instrinsik, kompensasi dan Pengawasan Pimpinan terhadap Kinerja Pegawai di Dinas Perhubungan Kota Gunungsitoli".

\section{METODE PENELITIAN}

Dari permasalahan yang telah diteliti, dipergunakan metode penelitian yakni deskriptif kuantitatif. Dalam penelitian ini terdapat juga Studi eksplorasi dengan tujuan penggambaran keadaan atau fenomena yang sedang terjadi. Digunakan pula kuisioner sebagai instrumen sehingga data terkumpul. Kuisioner ialah sebuah daftar pertanyaan dari orang lain agar memberi respon yang disesuaikan dengan permintaan pengguna.(Yayuk \& Sugiyono, 2019) memberikan pernyataan instrumen penilaian ialah sebuah alat yang dipergunakan untuk mengukur kuisioner pada pegawai sebagai sampel penelitian. Teknik yang digunakan untuk mengambil sampel yakni dipergunakan pada penelitian ini dengan model sensus yang mana keseluruh populasi menjadi sampel. Pada penelitian dipergunakan seluruh anggota populasi sebagai sampel dengan jumlah 40 orang.

Dinas Perhubungan Kota Gunungsitoli yakni sebuah organisasi yang berada dibawah naungan Kota Gunungsitoli berdasar Aturan Daerah Kota Gunungsitoli No. 8 Tahun 2016 berkenaan dengan pembentukan susunan Perangkat Daerah Kota Gunungsitoli dan Aturan Walikota No. 47 Tahun 2016 berkenaan dengan susunan Organisasi serta Tata Kerja. Lokasi lembaga tersebut beradapada Jl Arah Nias Tengah Km.7 Komplek Terminal atau Pasar Faekhu Kec. Gunungsitoli Selatan. Dinas perhubungan ini memiliki Tugas yakni didasarkan atas Perbantuan dan Otonomi. Kewenangan lembaga ini mengizinkan surat yang berkenaan dengan transportasi dan perhubungan sebagaimana urus izin usaha angkutan, angkutan umum, angkutan barang, izin trayek, serta kartu pengawasan angkutan penumpang umum, antar jemput, izin operasi sewa, operasi angkutan pariwisata, SPIT, dan sebagainya.

\section{HASIL DAN PEMBAHASAN}

Regresi linear berganda dipergunakan untuk melihat pengaruh antar variabel bebas yakni Motivasi Intrinsik, Kompensasi, Pengawasan Pimpinan, terhadap kinerja pegawai yang dilakukan pada 40 pegawai dengan perumusan:

$$
\begin{aligned}
& \mathrm{Y}=2,134+0,318 \mathrm{X} 1+0,453 \mathrm{X} 2+0,404 \mathrm{X} 3 \\
& \text { Keterangan: } \\
& \mathrm{Y} \quad=\text { Kinerja pegawai } \\
& \mathrm{X}_{1} \quad=\text { Motivasi intrinsik } \\
& \mathrm{X}_{2} \quad=\text { Kompensasi } \\
& \mathrm{X}_{3} \quad=\text { Pengawasan pimpinan }
\end{aligned}
$$

Berdasar persamaan tersebut dapat dijelaskan berikut:

a. Konstanta: 2,134 artinya tanpa variabel-variabel bebas motivasi intrinsik, kompensasi dan pengawasan pimpinan maka nilai kinerja pegawai adalah sebesar 2,134. 
b. Koefisien regresi 0,318 artinya bahwa jika motivasi intrinsik semakin baik dengan asumsi variabel lain tetap maka mampu meningkatkan kinerja pegawai.

c. Koefisien regresi 0,453 artinya bahwa jika kompensasi semakin baik dengan asumsi variabel lain tetap maka mampu meningkatkan kinerja pegawai.

d. Koefisien regresi 0,404 artinya bahwa jika pengawasan pimpinan semakin baik dengan asumsi variabel lain tetap maka mampu meningkatkan kinerja pegawai.

1. Pengaruh Motivasi Intrinsik terhadap Kinerja Pegawai

Hasil kuesioner variabel motivasi intrinsik yang disebarkan kepada pegawai di lingkungan Dinas Perhubungan Kota Gunungsitoli menunjukkan tingkat keberhasilan dengan bekerja secara maksimal untuk mencapai target kerja serta mempertahankan kualitas kerja. Keberhasilan kerja diukur dengan membandingkan perencanaan kerja setiap pegawai yang disusun pada awal tahun anggaran dengan penilaian sasaran kerja pegawai yang dinilai pada akhir tahun anggaran. Perencanan kerja merupakan turunan dari indikator kinerja utama (IKU) sebagai organisasi perangkat daerah urusan wajib pemerintahan bidang perhubungan. Pencapaian sasaran kerja pegawai berbanding lurus dengan kualitas kerja yang terjaga sesuai dengan standar yang telah ditentukan. Hasil kuesioner juga menunjukkan bahwa pegawai Dinas Perhubungan Kota Gunungsitoli memiliki penguasaan pengetahuan dan keterampilan di bidang kerja masing- masing. Kemampuan untuk menjalankan pekerjaan menjadi motivasi intrinsik pegawai dalam menjalani rutinitas seharihari tanpa terbebani.

Hal ini sesuai dengan pendapat (Budiman \& Steven, 2021)menyatakan bahwa Motivasi merupakan sebuah alasan keaktifan dan fungsi yang tidak dapat terangsang dari luar mengingat pada diri individu terdapat dorongan untuk menjalankan suatu hal. Dengan adanya motivasi instrisik dalam diri setiap pegawai Dinas Perhubungan Kota Gunungsitoli memunculkan upaya dan usaha semaksimal mungkin untuk mencapai sasaran kerja yang telah ditentukan.

Salah satu bentuk upaaya dan usaha pegawai Dinas Perhubungan Kota Gunungsitoli untuk meningkatkan kinerja dalam hal Pendapatan Asli Daerah (PAD) adalah dengan belajar keras untuk menguasai aplikasi pembuatan Pengujian Kendaraan Bermotor (PKB) berbasis digital yang diadakan sejak bulan maret tahun 2021 yang lalu. Untuk saat ini Pengujian Kendaraan Bermotor (PKB) berbasis digital Dinas Perhubungan Kota Gunungsitoli merupakan satu satunya layanan yang tersedia di kepualan Nias (4 kabupaten dan 1 kota) dan menjadi keunggulan Dinas Perhubungan Kota Gunungsitoli di banding Dinas Perhubungan lainnya yang ada di Kepulauan Nias.

Pengurusan Pengujian Kendaraan Bermotor (PKB) selama belum tersedinya di Dinas Perhubungan Kota Gunungsitoli, pelanggan harus mengurusnya di Padang Sidempuan yang tentunya membutuhkan biaya yang tidak sedikit dan memakan waktu yang cukup lama. Inventarisasi 
masalah yang dapat meningkatkan serta dapat menurunkan motivasi kerja pegawai Dinas Perhubungan Kota Gunungsitoli merupakan kunci utama pimpinan dan pemangku kepentingan dalam merencanakan pekerjaan berbasis partisipatif. Harapannya, pimpinan dapat mengedepankan kekuatan dan peluang yang dimiliki di Dinas Perhubungan Kota Gunungsitoli serta meminimalkan kelemahan dan ancaman sehingga setiap pegawai mampu dapat termotivasi untuk meningkatkan kinerja pegwai.

\section{Pengaruh Kompensasi terhadap} Kinerja Pegawai

$$
\text { Hasil pengujian hipotesis }
$$

menunjukkan kompensasi berpengaruh positif dan signifikan terhadap kinerja pegawai yang mana mereka menerima kompensasi dalam bentuk finansial dan nonfinansial. Hasil kuesioner menunjukkan pegawai Dinas Perhubungan Kota Gunungsitoli menerima kompensasi finansial dalam bentuk gaji, insentif, asuransi dan tunjangan lainnya sesuai dengan posisi dan jabatan masing-masing pegawai. Peningkatkan kinerja pegawai berdampak secara pribadi bagi pengembangan kapasistas diri pegawai, namun juga berdampak secara umum akan pencapaian tujuan lembaga. Hal ini sesuai dnegan pendapat (Satria \& Kuswara, 2013) yang mengemukakan bahwa Peluang promosi merupakan kesempatan setiap pegawai untuk memperoleh penambahan jumlah pendapatan dari kompensasi finansial yang diterima. Pegawai Dinas Perhubungan Kota Gunungsitoli berusaha untuk mencapai target kerja dan memperoleh penilaian sasaran kerja yang baik untuk mempermudah peluang kenaikan pangkat.

\section{Pengaruh Pengawasan Pimpinan} terhadap Kinerja Pegawai

$$
\text { Hasil pengujian hipotesis }
$$

menunjukkan pengawasan pimpinan berpengaruh positif dan signifikan terhadap kinerja pegawai di lingkungan Dinas Perhubungan Kota Gunungsitoli. Hasil kuesioner menunjukkan pimpinan Dinas Perhubungan Kota Gunungsitoli memiliki dasar dalam melaksanakan fungsinya sebagai pengawas dengan adanya penetapan peraturan Walikota Gunungsitoli yang mengatur pengawasan pimpinan. Dengan adanya peraturan tersebut, mempermudah pimpinan menjalankan fungsinya secara objektif, transparan dan terukur. Pimpinan Dinas Perhubungan Kota Gunungsitoli menjabarkan peraturan Walikota Gunungsitoli dalam bentuk SOP instansi. Harapannya, pengawasan pimpinan yang yang berjalan sesuai dengan peraturan memastikan setiap pegawi bekerja sesuai dengan peraturan yang telah ditetapkan sebelumnya.

Pengawasan pimpinan yang teratur dan dilaksanakan secara konsisten berperan meningkatkan kinerja pegawai Dinas Perhubungan Kota Gunungsitoli. Setiap pegawai menjalankan tugasnya sesuai dengan deskripsi kerja dan mengisi lembar evaluasi sesuai dengan kegiatan masing-masing pegawai. Produktivitas pegawai Dinas Perhubungan Kota Gunungsitoli meningkat seiring dengan hasil evaluasi pengawasan pimpinan, setiap pegawai Dinas Perhubungan Kota Gunungsitoli selalu memperbaiki dan 
mempersiapkan diri untuk memperoleh hasil evaluasi terbaik dari setiap pengawasan pimpinan.

\section{SIMPULAN}

Hasil penelitian ini diinginkan dapat dimanfaatkan sebagai acuan pada penelitian-penelitian selanjutnya yang berkaitan dengan variabel-variabel yang telah diteliti serta saran penelitian diantaranya dapat meningkatkan motivasi dan kompetensi dalam menjalankan kinerja pegawai dinas Perhubungan Kota Gunungsitoli

\section{DAFTAR PUSTAKA}

Budiman, J., \& Steven. (2021). Pengaruh Disiplin Kerja dan Motivasi Terhadap Kinerja Serta Dampaknya Terhadap Kepuasan Kerja. 5(1), $79-85$.

Karundeng, C. C. (2013). Pengaruh Iklim Organisasi terhadap Karyawan pada PT. TASPEN (Persero) Cabang Manado. Jurnal Acta Diurna, 2(3), 1-15. https://ejournal.unsrat.ac.id/index.php/act adiurnakomunikasi/article/view/2433/1968

Kusuma, A. G. P., \& Hidayat, W. (2021). Peningkatan Kinerja Organisasi TI Berdasarkan Metode DMAIC Dengan Pendekatan Frame Work ITIL V.3. 5(1), 3249.

Levina, P., \& Haan, M. De. (2019). Gaya Kepemimpinan Dengan Motivasi Kerja Perawat Di Rumah Sakit Jiwa. Jurnal Keperawatan, 7(2).

Putra, I. K. A. A. A., Syaifudin, A., \& Adinatha, N. N. M. (2014). Hubungan Gaya Kepemimpinan Kepala Ruangan Dengan Kinerja Pperawat Pelaksana Di Rumah Sakit Umum Daerah RAA Soewondo Pati. Prosiding Konferensi Nasional II PPNI Jawa Tengah 2014.

Qustolani, A. (2018). Pengaruh Kepuasan Kerja, Keadilan Prosedural Dan Kompensasi Terhadap Kinerja Perawat. Jurnal Ilmiah Manajemen \& Akuntansi, 4(Widodo 9).

Salawangi, G. E. (2019). Hubungan Motivasi Kerja Dengan Kinerja Perawat Di Instalasi Rawat Inap Rsud Liun Kendage Tahuna Kabupaten Sangihe. Kesmas, 7(5).
Saputra, B., \& Anindita, R. (2021). Peran Servant Leadership Dalam Meningkatkan Kepuasan Dan Loyalitas Karyawan Pada Industri Manufaktur. 5(1), 12-31.

Satria, R. O., \& Kuswara, A. (2013). Pengaruh Motivasi Dan Pelatihan Terhadap Kompetensi Kerja Serta Implikasinya Pada Produktivitas Pegawai Dinas Perhubungan Kota Bandung. Jurnal Ekonomi, Bisnis \& Entrepreneurship, $\quad 7(2), \quad 74-83$. http://jurnal.stiepas.ac.id/index.php/jebe/a rticle/view/31

Simarmata, R. M. (2021). Analisis Pengaruh Stres Kerja Dan Disiplin Kerja Terhadap Kepuasan Kerja (Studi Pada Pegawai PT Angkasa Pura II (Persero) Kantor Cabang Bandara Husein Sastranegara Bandung). $5(1), 63-78$.

Stephen, Robbins, S. P., Judge, T. A., \& Diana, P. (2015). Perilaku Organisasi. 2008.

Syamsurizal. (2021). Peran Manajemen Sumber Daya Manusia dalam Organisasi. JUSIE (Jurnal Sosial Dan Ilmu Ekonomi), 6(o1), 29-38.

https://doi.org/10.36665/jusie.v6iol.414

Tukiman, Purba, A. P. A., Insani, K. N., \& Paramastri, Z. H. (2021). Peningkatan Kedisiplinan Pegawai Melalui Pelatihan Kerja (Studi pada Dinas Tenaga Kerja Kota Bekasi). 5(1), 125-132.

Yaqin, A. A., \& Kristanto, A. (2012). Strategi Pemasaran Pendidikan di Madrasah Aliyah Unggulan Pondok Pesantren Amanatul Ummah Surabaya. Jurnal.

Yayuk, S., \& Sugiyono, S. (2019). Pengaruh kepemimpinan kepala sekolah dan biaya pendidikan terhadap kualitas proses belajar mengajar dan dampaknya dengan kompetensi lulusan SMK di Kabupaten Gunungkidul. Jurnal Akuntabilitas Manajemen Pendidikan, 7(1), 84-96. https://doi.org/10.21831/amp.v7i1.23758 